\title{
Topographic modulation of fault kinematics in the Himalaya and Tibet
}

\author{
Richard Styron \\ Earth Analysis, Saratoga, CA \\ richard.h.styron@gmail.com
}

\begin{abstract}
In many locations in the Himalaya and Tibet, extensional stepovers on strike-slip faults occur beneath pre-existing topographic highs. An influential physical model of orogens, explaining contemporaneous high-elevation normal faulting and low-elevation reverse faulting, holds that horizontal tectonic compression is invariant across the orogen while vertical stress varies with topography, changing the balance of stresses. This model is two-dimensional and requires topography to be supported isostatically, and therefore cannot fully describe strike-slip to normal fault transitions beneath mountains to small mountain ranges, as this is a threedimensional deformation field and topography of this wavelength is supported isostatically. I introduce a 3D elastic model describing the modulation of fault kinematics by shorter-wavelength topographic stress, and show how the model can place constraints on the tectonic stress field. I then calculate the topographic stress field on the Western Nepal Fault System, and use topographic stresses and observed fault kinematics to invert for the tectonic stress field. The results yield a maximum tectonic compression of $0-0.2$ rho gz and minimum tectonic compression of $-0.1-0.1$ rho $\mathrm{gz}$, and reproduce kinematics from normal, strike-slip and thrust faults and earthquakes in and around western Nepal, including the 2015 Gorkha earthquake. This demonstrates that where vertical and a horizontal principal stress are near equal, $1-10 \mathrm{~km}$ scale variations in topography can change fault kinematics, and that pre-existing topography can influence the location of subsequent faults and stepovers.
\end{abstract}

\section{Introduction}

In the Himalaya and Tibet, it has long been observed that thrust earthquakes take place at the low-elevation rangefronts surrounding the plateau, while normal and strike-slip earthquakes occur in the elevated interior (e.g., Molnar and Tapponnier, 1978; Elliott et al., 2010) (Figure a). Molnar and Lyon-Caen (1988) offered an influential physical explanation for this simultaneous low-elevation reverse faulting and high-elevation normal faulting: Horizontal tectonic compression $\sigma_{H}$ (integrated over the crustal column) is essentially spatially invariant, while vertical compression $\sigma_{V}$ at depth varies with the height of the overlying terrain. At low elevations, $\sigma_{H}>\sigma_{V}$, leading to crustal thickening, while at higher elevations, $\sigma_{V}>\sigma_{H}$, causing crustal extension.

These observations and hypotheses concern entire orogens. Whether they apply at smaller scales is a natural question, though unaddressed. The analytical model by Molnar and Lyon-Caen (1988) rests on the assumption of isostatically-supported topography, which is valid over $10^{2}-$ $10^{3} \mathrm{~km}$ scales (i.e., orogens), but may not be over $1-10 \mathrm{~km}$ (mountain to mountain range) scales, where topography is mostly supported elastically (e.g., Bollinger et al. 2004). Additionally, topographic slopes at these scales may impart locally substantial stresses in the upper crust, which may be smoothed out at larger scales. The motivating observations are typically earthquake focal mechanisms, which are too sparse spatially and from too short a time window to fully describe high-resolution deformation.

However, neotectonic mapping provides a more complete description of the deformation field integrated over longer timescales $\left(10^{3}-10^{5}\right.$ years) and offers better spatial coverage and resolution as well. Recent neotectonic maps of the Himalaya and Tibet reveal a rich interaction between fault type and elevation over 1-100 km scales (Figure ). These observations document changes in the kinematics of large fault systems where the faults cross smaller topographic features (ridges to mountain ranges); as the topography is often known to be older than the active faults, it is likely that topography modifies fault kinematics at these scales as well, though the mechanisms may be different than in the orogenscale, isostatic case. Documenting this phenomenon is the first objective of this study.

If topography is capable of modifying fault kinematics, then the total (tectonic plus topographic) stress field must resolve on the faults with shear stress directions that are consistent with the directions of fault slip. Therefore, if the topographic stresses can be calculated, these stresses and the fault kinematics may be used to constrain the tectonic stress field. Precise estimation of tectonic stress is a major advancement for understanding earth processes. Stress is generally unknown at the order of magnitude level, despite 

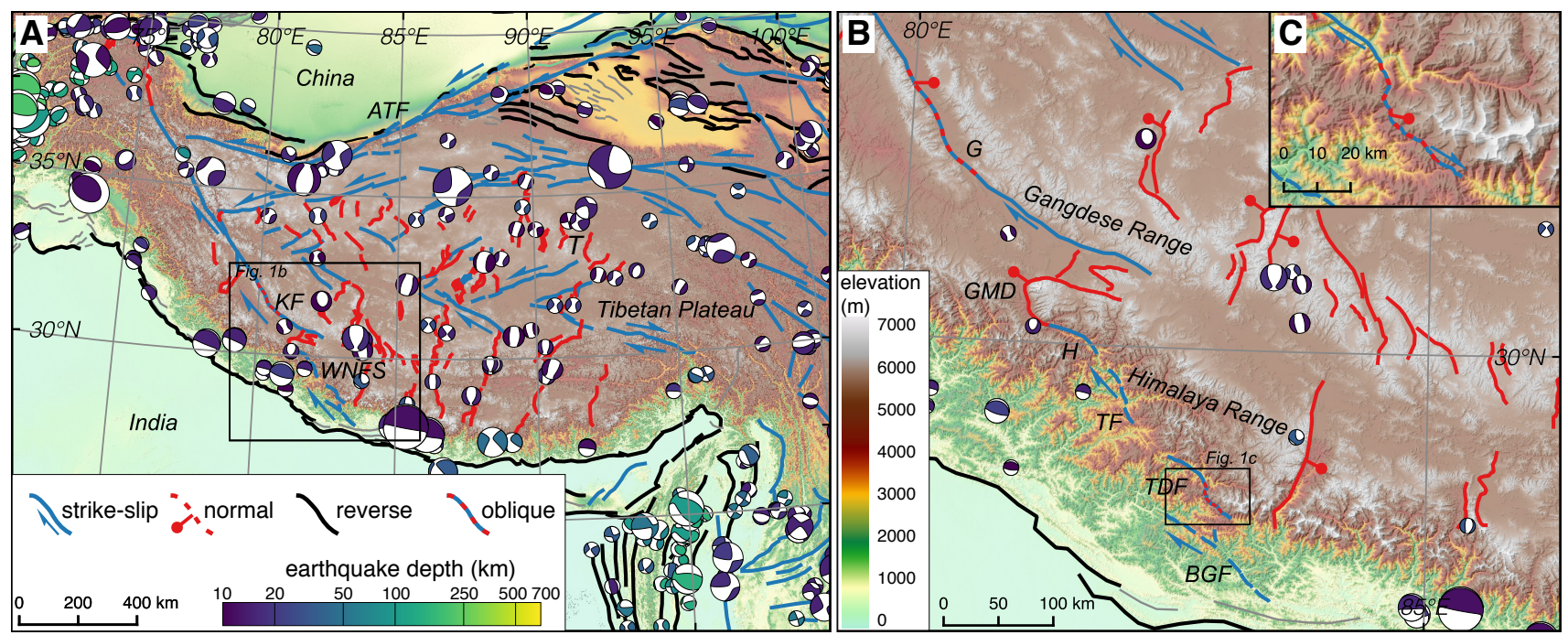

Figure 1: Active faulting of the Tibetan plateau. 1a: View of the orogen. 1b: Map of the southeastern KF and WNFS. 1c: Map of the Tibrikot-Dogari segment of the WNFS. KF=Karakoram Fault. ATF=Altyn Tagh Fault. GM=Gurla Mandhata Detachment. G=Gar Basin. H=Humla Fault. TF=Talphi Fault. TDF=Tibrikot-Dogari Faults. BGF=Bari Gad Fault. Focal mechanisms from the GCMT catalog (Ekström et al. 2012). Faults from HimaTibetMap v. 1.2 (Styron et al., 2010)

being a fundamental physical property of the earth, and the primary control on the earth's deformation. Accurate stress estimates are critical for understanding the distribution of seismicity in time and space, as well as the physical properties and evolution of faults and orogens. This quantification is the second objective of this study.

\section{Fault kinematic transitions and topog- raphy in Tibet and the Himalaya}

Many fault zones within the Tibetan plateau and vicinity show transitions in fault kinematics with changes in topography (Figure ). These are best displayed in transtensional fault zones in the elevated interior of the plateau, consistent with the hypothesis that Tibet is at the maximum elevation that can be sustained by horizontal tectonic compression (e.g., Molnar and Lyon-Caen, 1988). For example, the sinistral Longmu Co-Gozha Co fault system has a major extensional stepover where the fault crosses the western Kunlun Shan, where the $2008 M_{w} 7.1$ Yutian earthquake occurred (Xu et al., 2013). Left-lateral faulting continues to the northeast of the high mountains as the faults merge with the Altyn Tagh Fault. Similarly, the transtensional Yibug Caka and Mugu Purou rifts in central Tibet show local extensional stepovers where topography is elevated (Taylor et al., 2003; Ratschbacher et al., 2011), and the conjugate strikeslip systems to their south link to rifts where regional elevation steps higher. This is evident in individual earthquakes as well: Chang et al. (2016) observe localized extensional fault scarps near isolated high mountains on the western end of the $2001 M_{w} 7.8$ Kunlun rupture.

Additionally, most isolated topographic highs on the plateau outside of transtensional zones are cut by active normal faults that do not extend far into the lower surroundings; the Gangdese (Figure b) and Tanggula Ranges (Figure a) are prime examples. In these locations, the horizontal differential stress may not be great enough for fault failure, but high $\sigma_{V}$ underneath the ranges causes localized normal faulting.

Perhaps the most clear example of topographic modulation of fault kinematics is on the southeastern KarakoramWestern Nepal Fault System, which undergoes three distinct extensional stepovers, one for each instance in which the fault system intersects pre-existing topographic highs (Figure b).

The Karakoram Fault (KF) is a major dextral fault on the boundary between the northwestern Himalaya and southwestern Tibet. The KF is purely strike-slip through most of its length but has a transtensional zone where it cuts through the Gangdese Range called the Gar Basin (Sanchez et al., 2010), and terminates at the Pulan Graben (dominated by the Gurla Mandhata Detachment, GMD) where the KF hits the northern Himalaya (Murphy et al., 2002). Some or all of the KF slip is transferred to the GMD and south into the Himalaya along the Humla Fault (Murphy and Burgess, 2006).

Though the nature of fault connectivity remains unclear, it is likely that dextral slip continues through the Himalayan wedge along the Western Nepal Fault System (WNFS). Dextral and normal slip has been observed on the Tibrikot and 
Dogari segments of the WNFS (Murphy et al., 2014; Silver et al., 2015). Additional dextral fault offsets have been observed on the Talphi and Bari Gad Faults to the northwest and southeast of the Tibrikot fault (Nakata, 1989).

A striking feature of the overall geometry of the KFGMD-WNFS faults is that extensional stepovers occur wherever the strike-slip faults encounter locally high terrain (Figure b). The higher terrain in all cases predates the strike-slip faulting along the KF-WNFS system: The Gangdese Range was a regional topographic high and sediment source by the Oligocene (Leary et al., 2016), predating the post-middle Miocene faulting in Gar Basin (Sanchez et al., 2010), while the Himalaya was uplifted to near modern elevation by the Miocene (Garzione et al., 2000), before extension. Extension along the GMD has resulted in great uplift of the footwall $(>7700 \mathrm{~m})$, but normal faulting must cause a net decrease in regional elevation despite local footwall uplift. Additionally, faults associated with the current dextral-normal slip regime cut north-dipping brittle and ductile fault fabrics associated with the uplift of the Himalaya (Silver et al., 2015). It may be that the WNFS becomes transpressive in its low-elevation southern extent, as the Bari Gad fault nears the active Himalayan frontal folds and thrusts; this is observed on the symmetrical Altyn Tagh fault system on Tibet's northern margin (Cowgill et al., 2004).

\section{Three-dimensional topographic and tectonic stresses}

The regional-scale topography and stress relationship described here share the central concept developed in the orogen-scale models, that changes in fault style result from variable, primarily vertical topographic stresses superposed on relatively invariant, primarily horizontal tectonic stresses (Figure ). However, the regional model has some key differences, as well.

First, this problem is inherently three-dimensional. Faults of all kinematic types in the Himalaya and Tibet accommodate $\sim \mathrm{N}-\mathrm{S}$ shortening, $\sim \mathrm{E}-\mathrm{W}$ extension, or both (Figure $)$. This allows us to expand the model's dimensionality: The two-dimensional model has $\sigma_{H}>\sigma_{V}$ (reverse faulting) in the lowlands and $\sigma_{V}>\sigma_{H}$ (normal faulting) in the highlands. But we can add a dimension, with $\sigma_{H}>\sigma_{h}>\sigma_{V}$ in the lowlands, $\sigma_{H}>\sigma_{V}>\sigma_{h}$ in regions of moderate elevations, and $\sigma_{H}>\sigma_{h}>\sigma_{V}$ in the highlands, where $\sigma_{h}$ is the minimum principal horizontal stress (Figure ). This expansion enables us to consider faults of all styles and orientations (not only those striking perpendicularly to the 2D model's cross-section), and to calculate the full 3D stress tensor field. Furthermore, if $\sigma_{H}$ and $\sigma_{h}$ are not near equal, there may be a large elevation gap between reverse and normal faulting, leading to large uncertainties in stress estimations in the 2D model (Richardson and Coblentz, 1994). By considering all three fault styles and principal stresses, the uncertainties are much reduced.

Secondly, shorter-wavelength topography is supported elastically rather than isostatically (e.g., Bollinger et al., 2004). This means that topographic stresses may vary dramatically over short horizontal and vertical distances, slopes may impart locally strong horizontal stress, and the perturbation to the stress field produced by topography extends outward and downward rather than simply being a simply vertical sum of the weight of the overlying rocks. As a result, short-wavelength topographic stresses may be spatially variable and resolve very differently along-strike and downdip on a through-going fault.

Finally, the regional model does not require invariance of tectonic stress over $10^{2}-10^{3} \mathrm{~km}$, only over $10^{0}-10^{2}$ $\mathrm{km}$. Tectonic stress may change over longer distances due to changes in boundary conditions (e.g., plate driving forces) and lithospheric rheology. While Molnar and Lyon-Caen (1988) do provide compelling arguments for stress invariance across orogens, such invariance is not a requirement of this model. Consistent application of stress inversions using the regional model (as below) in many locations throughout an orogen may serve as a test of orogen-scale tectonic stress invariance.

\section{Topographic stress}

To test the hypothesis that the topography-fault kinematics relationship is based on a varying topographic stress superposed on a laterally-invariant tectonic stress field, I seek to reproduce the observed fault kinematics by calculating the topographic and tectonic stress fields, and resolving them on 3D fault models in the region, following methods outlined in Styron and Hetland (2015). The topographic stress

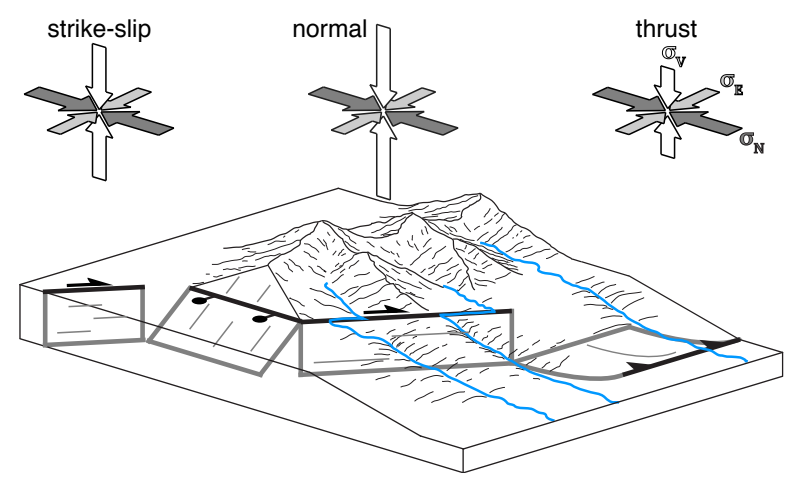

Figure 2: Schematic block diagram demonstrating the relationships between stress, topography and faulting. $\sigma_{H}$ and $\sigma_{h}$ (represented by $\sigma_{E}$ and $\sigma_{N}$ ) are invariant across the region though $\sigma_{V}$ varies with topography, changing fault kinematics. 
calculations are deterministic, as topography is well known and allowable variation in the Earth's elastic moduli does not meaningfully modify the results. The tectonic stresses are solved for using a Bayesian inversion scheme. To avoid overfitting and assess the veracity of results beyond the study region, the inversion is performed on two relatively well-studied faults, the Gurla Mandhata and Tibrikot-Dogari faults, and then validated on additional deformation data in the region: a coseismic slip model from the $2015 M_{w} 7.8$ Gorkha, Nepal earthquake (Galetzka et al., 2015) and preGorkha focal mechanisms throughout the region. The two faults modeled here were selected because the fault geometry and kinematics are well known through field (Murphy et al., 2002; Silver et al., 2015) and thermochronological (McCallister et al., 2014) studies; the other faults in the WNFS have not received sufficient study to model confidently.

The topographic stresses are calculated through elastic halfspace methods following Liu and Zoback (1992) and Styron and Hetland (2015), by a convolution loading functions describing the distribution of topographic loading on the halfspace surface with Green's functions describing the propagation of stresses in the halfspace from vertical and horizontal point load on the surface. This results in a 3D array with the $3 \times 3$ topographic stress tensor calculated at every point (500 $\mathrm{m}$ horizontal resolution, $1 \mathrm{~km}$ vertical resolution) in a $\sim 840 \times 700 \mathrm{~km}$ region. The halfspace surface is set to sea level, though calculations above $1500 \mathrm{~m}$ below sea level are discarded due to concerns of overestimating shallow topographic stress where slopes are steep, a known limitation of the perturbation-expansion method used.

The Gurla Mandhata and Tibrikot-Dogari fault traces are extended to depth based on contraints from structural data and thermal modeling. The fault surfaces are made into a triangular mesh, and the stress tensors are then interpolated onto them using barycentric interpolation. The rake of the maximum shear stress on each fault patch is calculated based on the strike and dip of that fault patch.

\section{Tectonic stress}

I then solve for the allowable tectonic stresses through a Bayesian inversion, seeking to minimize the misfit between the rake of the resolved total stress tensor (topographic plus tectonic) and the observed slip rake. The tectonic stress field $T$ is assumed to increase linearly with depth below the halfspace surface (Townend and Zoback, 2000), and so is scaled to be a fraction of lithostatic pressure below the halfspace surface (i.e., $\rho g z$, where $\rho=2700 \mathrm{~kg} \mathrm{~m}^{-3}$ ). $T$ is horizontal, and has three components: $T_{\max }, T_{\min }$ and $T_{a z}$ (the azimuth of $\left.T_{\max }\right) . T_{\max }$ has a uniform prior from [0-1) $\rho g z, T_{\min }$ has a uniform prior of $[-1-1) T_{\max }\left(T_{\min }\right.$ is by definition smaller than $T_{\max }$ and therefore cannot be independently defined in terms of $\rho g z$ ), and $T_{a z}$ has a uniform prior of $0^{\circ}-359^{\circ}$. Each sample of $T$ is then rotated to $T_{N-S}, T_{E-W}$, and $T_{N-E}$ (the

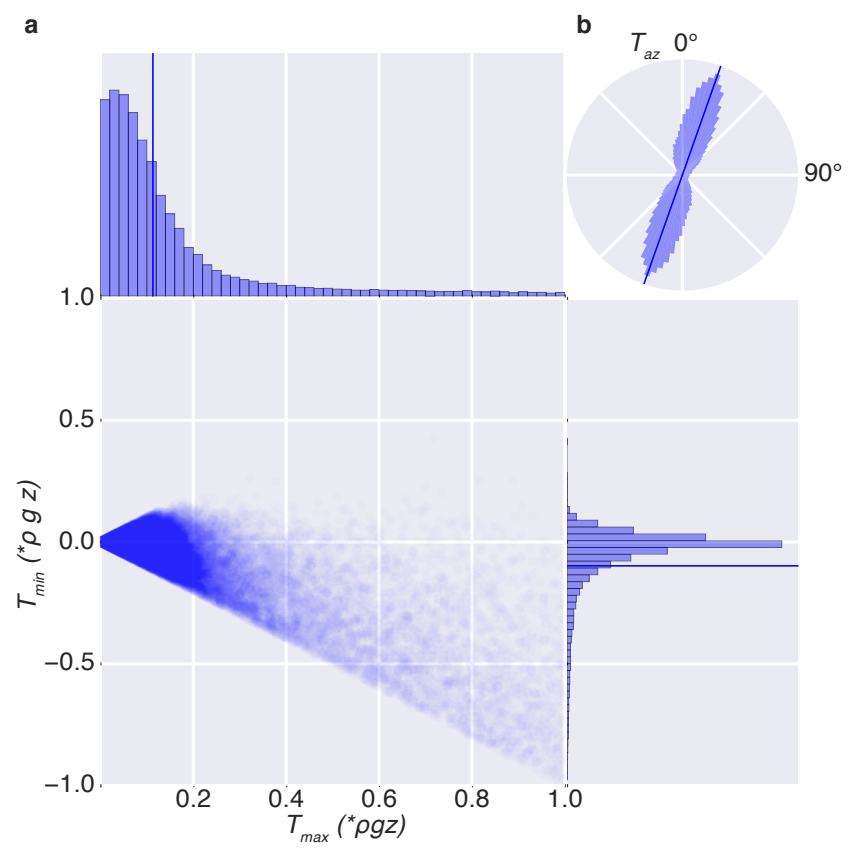

Figure 3: A:Scatterplot with marginal histograms of the inversion results for $T_{\max }$ and $T_{\min }$. B: Rose diagram for $T_{a z}$.

horizontal shear stress) and added to the topographic stress tensor at each point.

For each of 1 million samples, the mean rake misfit $\lambda^{m}$ is calculated as the mean of the absolute value of the rake differences between the observed slip rake and modeled maximum shear stress rake. Then, the relative likelihood of each sample set is calculated as $p(D \mid T)=\frac{\exp \left(\kappa \cos \lambda^{\bar{m}}\right)}{\exp \left(\kappa \cos \lambda_{\max }^{\bar{m}}\right)}$ where $\kappa$ is a scale term, reflecting the uncertainty in the rake data.

The posteriors $p(T \mid D)$ are then sampled proportionally to the relative likelihood, following Bayes' rule: $p(T \mid D) \propto$ $p(T) p(D \mid T)$.

\section{Results}

Topographic stresses tend to be in the direction of fault slip, particularly for the dip-slip faults, including the Gorkha rupture plane, which is loaded in a thrust sense by slope-induced subhorizontal compression. Tectonic stresses are not working against topography in the Himalaya.

The results of the tectonic stress inversion are shown in Figure . The maximum posterior values for the joint posterior distribution (i.e., the location of the highest posterior probability density in the 3-variable space) are $T_{\max }=$ $0.1 \rho g z,\left(\sim 2.7 \mathrm{MPa} \mathrm{km}{ }^{-1}\right.$ depth$), T_{\min }=-0.1 \rho g z$, and $T_{a z}=20^{\circ}$. The mean absolute misfit between the observed and modeled fault rakes for the maximum posterior model is $26^{\circ}$. The $1-\mathrm{D}$ marginals are somewhat similar; $T_{\max }$ has a mode at $<0.05 \rho g z, T_{\min }$ has a mode near 0 , with a tensile 
skew, and $T_{a z}$ has a mode at $20^{\circ}$, parallel to the direction of the Indo-Asian convergence (e.g., Gan et al., 2007).

These results agree well with regional earthquake data not used in the inversion: The maximum-likelihood tectonic stresses were scaled to depth and added to the topographic stress tensor at each point in a coseismic slip model from the 2015 Gorkha, Nepal earthquake (Galetzka et al., 2015) and pre-Gorkha focal mechanisms from the central Himalaya and southern Tibet (ISC). The total stress tensors were resolved on each fault plane and the predicted shear stress rake was compared to the observed slip rake. The rakes matched very well $\left(<30^{\circ}\right.$ misfit $)$ for nearly all data points, regardless of whether the data were from thrust, normal or strike-slip earthquakes (Figure S1). This confirms the predictive power of this simple model where spatially-varying topographic stress coupled with depth-scaled tectonic stress control a complicated deformation field.

To test the effects of topographic stress (versus simply fault geometry) on replicating the shear stresses on the faults, the stress inversion procedure was repeated without topographic stresses on the fault planes, while holding all else constant. The results yield a most-likely model with $T_{\max }=0.05 \rho g z, T_{\min }=-1.15 \rho g z$, and $T_{a z}=18^{\circ} ; \lambda^{m}$ is about $10^{\circ}$ higher. The strong tension for $T_{\min }$ is required to induce normal-sense shear on the extensional stepovers in the absence of strong vertical compression underneath topography. Though the misfit is acceptable, it is unclear how orogen-parallel tension greater than $\rho g z$ could be generated in the Himalaya; block divergence due to variably-oblique convergence along the curved Himalayan front should induce some tension (McCaffrey and Nábělek, 1998), although $\rho g z$ is quite high. Additionally, unlike topographic stress, tectonic stress does not predict the location of extensional stepovers, it simply is able to match the slip rake on the existing stepovers to some degree.

These stresses are consistent with Himalayan thrusting: $T_{\max }=0.1 * \rho g z \approx 7 \mathrm{MPa}$ on a $10^{\circ}$ dipping plane at $15 \mathrm{~km}$, which is approximately equal to the location and magnitude of the maximum stress drop ( $\sim 8 \mathrm{MPa}$ ) of the Gorkha earthquake (Galetzka et al., 2015), suggesting that tectonic stress drop may have been locally complete during this earthquake. However, shear stresses from topography on the Gorkha fault plane are $>20 \mathrm{MPa}$ here, so total shear stress drop was not complete.

\section{Discussion}

In Tibet and the Himalaya, topography likely modulates fault kinematics over $\sim 10 \mathrm{~km}$ scales by locally changing the relative magnitudes of $\sigma_{V}$ to $\sigma_{H}$ and $\sigma_{h}$. Pre-existing topographic highs produce high $\sigma_{V}$ in the crust beneath, causing extensional stepovers in younger strike-slip faults cutting through the topography. This phenomenon is only pos- sible where the larger-scale balance of stresses is such that $\sigma_{V}>\sigma_{H}$ under topographic highs but $\sigma_{H}>\sigma_{V}$ in adjacent lower locations. By computing topographic stress, the orientions and magnitudes of $\sigma_{H}$ and $\sigma_{h}$ can be tightly constrained.

In the study areas, the topographic relief (not necessarily the modern elevation) predates the current tectonic regime and associated faults, and is therefore capable of controlling the location of releasing bends in strike-slip faults, as well as isolated grabens (e.g., in the Gangdese range). This may be common in orogens with a polyphase or protracted history (yielding enough paleorelief) which finally reach a broad equivalence between $\sigma_{V}$ and $\sigma_{H}$. However, evidence of this process may be erased with erosion, and the process may even reverse as stepover-produced topography builds: Cowgill et al. (2004) suggest that the kinematics of some stepovers on the Altyn Tagh fault change due to increasing topography and $\sigma_{V}$.

The tectonic stresses estimated are, perhaps, low for creating the world's current highest mountain range. They are significantly lower than those estimated at $T_{\max }=0.5-$ $1 \rho g z$ in eastern Tibet with the same methods (Styron and Hetland, 2015), or $T_{\max }=1.0 \rho g z$ measured from the upper $2.5 \mathrm{~km}$ of the SAFOD pilot hole on the San Andreas (Hickman and Zoback, 1994). However, as differential stress is limited by the strength of faults, low $T_{\max }$ may be due to a weak Main Himalayan thrust, marking a similarity with subduction zone megathrusts (e.g., Houston, 2015).

\section{References}

Bollinger, L., Avouac, J. P., Cattin, R., \& Pandey, M. R. (2004). Stress buildup in the Himalaya. Journal of Geophysical Research: Solid Earth, 109(B11).

Chang, H., Li, L. Y., Molnar, P., \& Niemi, N. A. (2016). Activation of a Minor Graben and Pull-Apart Basin Just East of Bukadaban during the 2001 Kunlun Earthquake (Mw 7.8). Bulletin of the Seismological Society of America.

Elliott, J. R., Walters, R. J., England, P. C., Jackson, J. A., Li, Z., \& Parsons, B. (2010). Extension on the Tibetan plateau: recent normal faulting measured by InSAR and body wave seismology. Geophysical Journal International, 183(2), 503-535.

Galetzka, J., Melgar, D., Genrich, J.F., Geng, J., Owen, S., Lindsey, E.O., Xu, X., Bock, Y., Avouac, J.P., Adhikari, L.B. and Upreti, B.N., 2015. Slip pulse and resonance of the Kathmandu basin during the 2015 Gorkha earthquake, Nepal. Science, 349(6252), pp.1091-1095.

Garzione, C.N., Dettman, D.L., Quade, J., DeCelles, P.G. and Butler, R.F., 2000. High times on the Tibetan Plateau: Paleoelevation of the Thakkhola graben, Nepal. Geology, 28(4), pp.339-342.

Houston, H. (2015). Low friction and fault weakening 
revealed by rising sensitivity of tremor to tidal stress. Nature Geoscience, 8(5), 409.

International Seismological Centre, On-line Bulletin, http://www.isc.ac.uk, Internatl. Seismol. Cent., Thatcham, United Kingdom, 2013.

Leary, R., Orme, D.A., Laskowski, A.K., DeCelles, P.G., Kapp, P., Carrapa, B. and Dettinger, M., 2016. Along-strike diachroneity in deposition of the Kailas Formation in central southern Tibet: Implications for Indian slab dynamics. Geosphere, 12(4), pp.1198-1223.

Liu, L. and Zoback, M.D., 1992. The Effect of Topography on the State of Stress in the Crust: Application to the Site of the Cajon Pass Scientific Drilling Project. Journal of Geophysical Research, 97(B4), pp.5095-5108.

McCaffrey, R. and Nabelek, J., 1998. Role of oblique convergence in the active deformation of the Himalayas and southern Tibet plateau. Geology, 26(8), pp.691-694.

McCallister, A.T., Taylor, M.H., Murphy, M.A., Styron, R.H. and Stockli, D.F., 2014. Thermochronologic constraints on the late Cenozoic exhumation history of the Gurla Mandhata metamorphic core complex, Southwestern Tibet. Tectonics, 33(2), pp.27-52.

Molnar, P. and Lyon-Caen, H., 1988. Some simple physical aspects of the support, structure, and evolution of mountain belts. Geological Society of America Special Papers, 218, pp.179-208.

Molnar, P. and Tapponnier, P., 1979. Active tectonics of Tibet. Journal of Geophysical Research: Solid Earth, 83(B11), pp.5361-5375.

Murphy, M.A. and Burgess, W.P., 2006. Geometry, kinematics, and landscape characteristics of an active transtension zone, Karakoram fault system, southwest Tibet. Journal of Structural Geology, 28(2), pp.268-283.

Murphy, M.A., Taylor, M.H., Gosse, J., Silver, C.R.P., Whipp, D.M. and Beaumont, C., 2014. Limit of strain partitioning in the Himalaya marked by large earthquakes in western Nepal. Nature Geoscience, 7(1), pp.38-42.

Murphy, M.A., Yin, A., Kapp, P., Harrison, T.M., Manning, C.E., Ryerson, F.J., Lin, D. and Jinghui, G., 2002. Structural evolution of the Gurla Mandhata detachment system, southwest Tibet: Implications for the eastward extent of the Karakoram fault system. Geological Society of America Bulletin, 114(4), pp.428-447.

Nakata, T., 1989. Active faults of the Himalaya of India and Nepal. Geological Society of America Special Papers, 232, pp.243-264.

Richardson, R.M. and Coblentz, D.D., 1994. Stress modeling in the Andes: Constraints on the South American intraplate stress magnitudes. Journal of Geophysical Research: Solid Earth, 99(B11), pp.22015-22025.

Sanchez, V.I., Murphy, M.A., Dupré, W.R., Ding, L. and Zhang, R., 2010. Structural evolution of the Neogene Gar Basin, western Tibet: Implications for releasing bend development and drainage patterns. Geological Society of Amer- ica Bulletin, 122(5-6), pp.926-945.

Silver, C.R., Murphy, M.A., Taylor, M.H., Gosse, J. and Baltz, T., 2015. Neotectonics of the Western Nepal Fault System: Implications for Himalayan strain partitioning. Tectonics, 34(12), pp.2494-2513.

Styron, R.H. and Hetland, E.A., 2015. The weight of the mountains: Constraints on tectonic stress, friction, and fluid pressure in the 2008 Wenchuan earthquake from estimates of topographic loading. Journal of Geophysical Research: Solid Earth, 120(4), pp.2697-2716.

Styron, R., Taylor, M. and Okoronkwo, K., 2010. Database of active structures from the Indo-Asian collision. Eos, Transactions American Geophysical Union, 91(20), pp.181-182.

Taylor, M., Yin, A., Ryerson, F.J., Kapp, P. and Ding, L., 2003. Conjugate strike-slip faulting along the BangongNujiang suture zone accommodates coeval east-west extension and north-south shortening in the interior of the Tibetan Plateau. Tectonics, 22(4).

Townend, J. and Zoback, M.D., 2000. How faulting keeps the crust strong. Geology, 28(5), pp.399-402. 

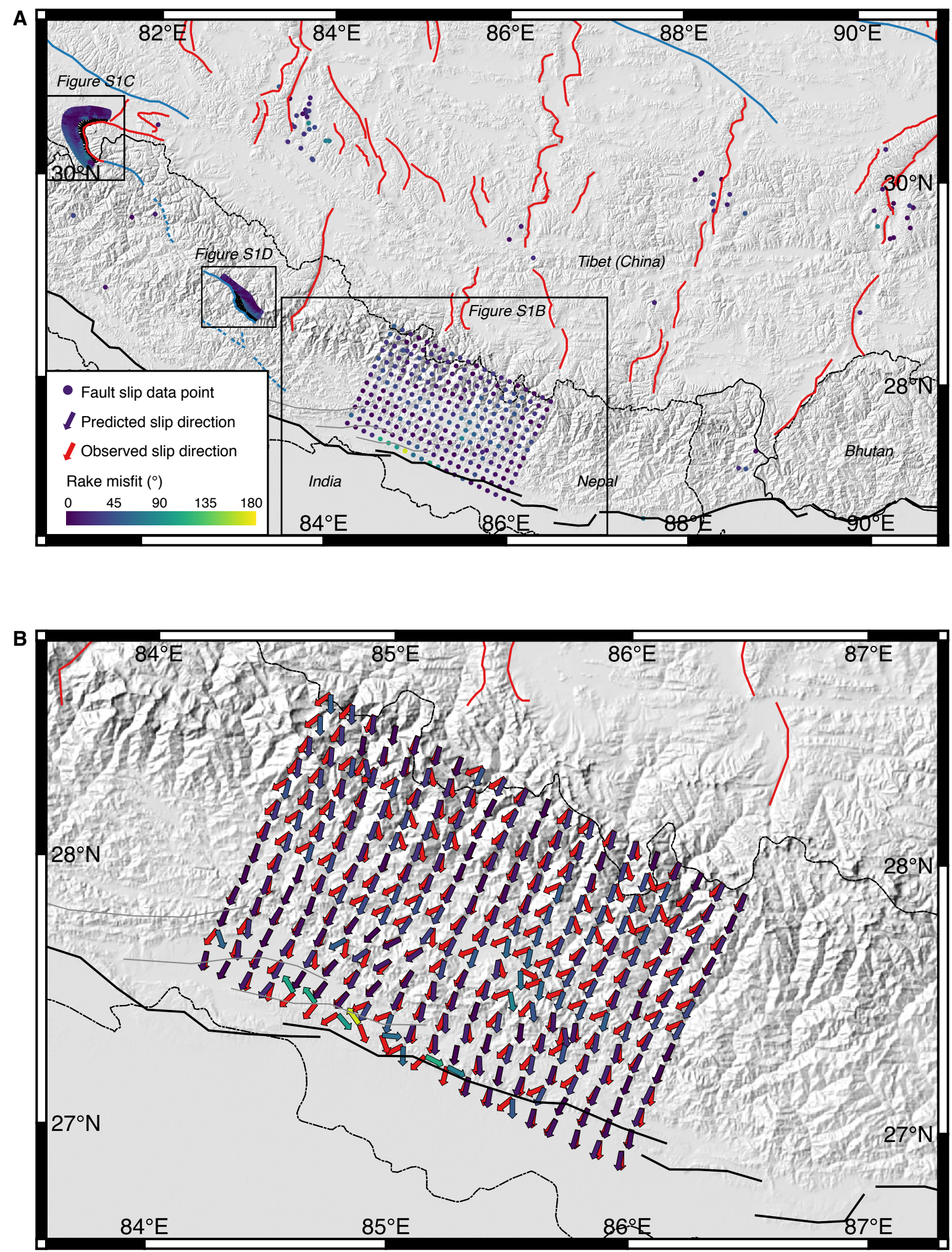

Figure S1: A: Maps of south-central Tibet and the Nepal Himalaya showing the goodness of fit of the model results. B: Map of the results for the 2015 Gorkha earthquake (from Galetzka 2015). Note that the observed rakes (in red) show much greater scatter than the modeled rakes, which may be a modeling artefact. C: Map of the Gurla Mandhata detachment showing the observed and modeled rakes, and fault mesh. D: Map of the Tibrikot-Dogari fault showing the observed and modeled rakes, and fault mesh. 

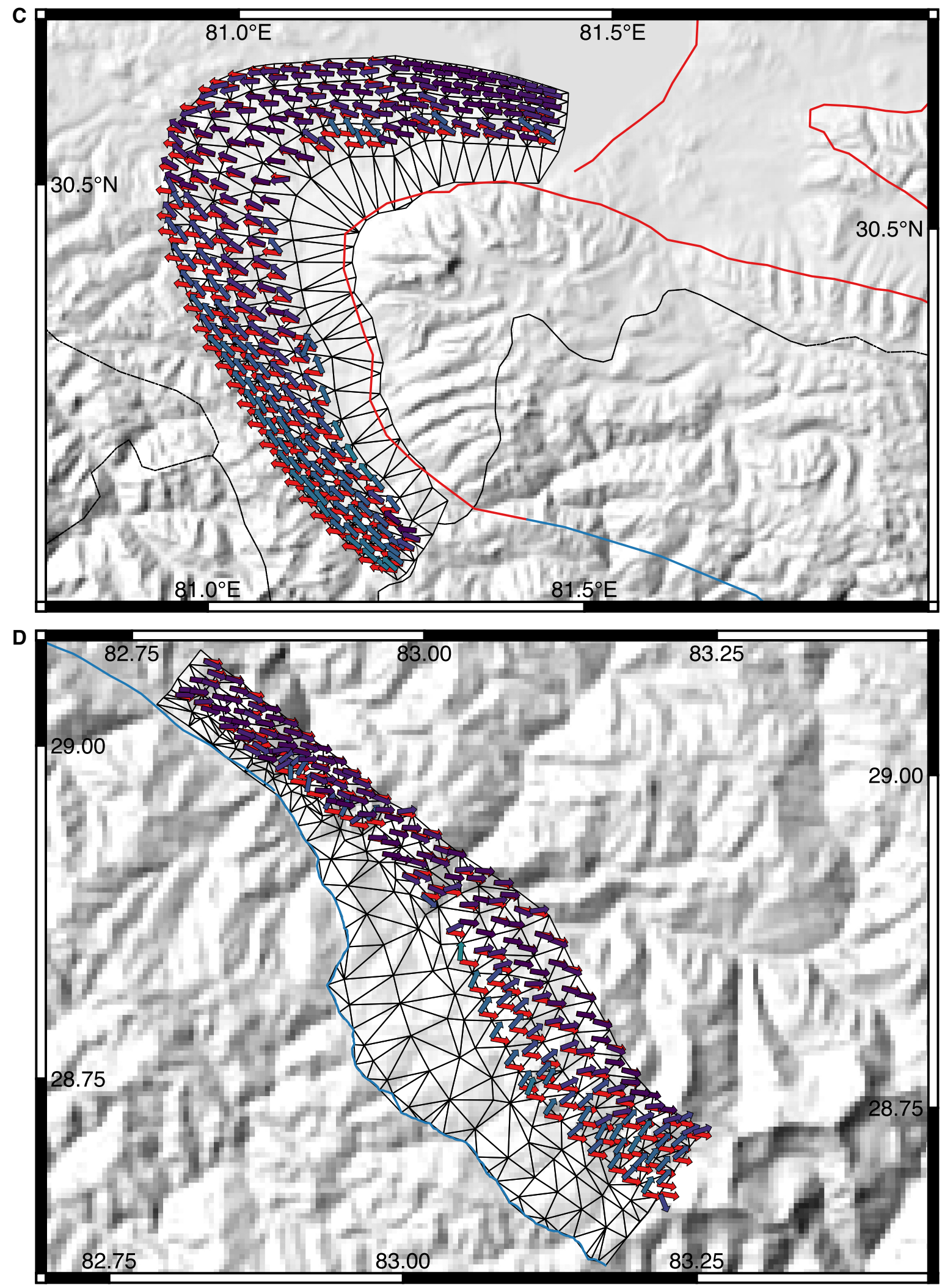

Figure S2: C: Map of the Gurla Mandhata detachment showing the observed and modeled rakes, and fault mesh. D: Map of the Tibrikot-Dogari fault showingthe observed and modeled rakes, and fault mesh. 